\title{
THE EFFECT OF LATE PRETERM BIRTH ON SURVIVAL OF INFANTS WITH MAJOR
} CONGENITAL HEART DEFECTS

\author{
M.A. Attar ${ }^{1}$, A.W. Swenson ${ }^{1}$, R.E. Dechert ${ }^{2}$, R.E. Schumacher ${ }^{1}$ \\ ${ }^{I}$ Pediatrics, ${ }^{2}$ Critical Care Support Services, University of Michigan Health System, Ann Arbor, MI, USA
}

\begin{abstract}
Aim: We evaluated the effect of late preterm delivery on hospital mortality of newborn infants with major congenital heart defects (CHD).

Methods: Retrospective review of records of infants with major CHD, born at or after 34 weeks, cared for in a single tertiary perinatal center between 1999 and 2009. Factors associated with death prior to discharge from the hospital were ascertained using univariate and multivariate analyses. We did not include infants with isolated atrial septal defects, patent ductus arteriosus, ventral septal defects, coarctation of the aorta, arrhythmias or cardiomyopathies. Variables such as the presence non-cardiac congenital anomalies, intrauterine growth restriction, place of birth, intubation in the delivery room, race or gender were included in the logistic regression analysis.
\end{abstract}

Results: Of the 753 infants with CHD, 115 were born at 34-36 weeks. CHD consisted of hypoplastic left heart syndrome $(34.8 \%)$, transposition of the great arteries $(24 \%)$, pulmonary atresia $(12 \%)$, tetralogy of Fallot $(9.3 \%)$, double outlet right ventricle $(7.2 \%)$, single right ventricle $(6.4 \%)$, interrupted aortic arch $(5.8 \%)$, tricuspid atresia $(5 \%)$, total anomalous pulmonary venous return $(4.6 \%)$, truncus arteriosus $(3.7 \%)$, common atrioventricular canal $(3.3 \%)$ and pentalogy of Cantrell $(<1 \%)$. White race $(\mathrm{OR}, 95 \% \mathrm{CI}),(0.6$, $0.39-0.95)$, late preterm delivery $(2.7,1.69-4.3)$, and need for intubation in the delivery room $(3.8,2.3-6.1)$ were identified as independent risk factors for death.

Conclusions: In a population of infants with major CHD, delivery during the late preterm period was independently associated with increased odds of death compared to delivery at more mature gestational ages. 